\title{
Anatomy of Extramuscular Soleus Veins: Clinical Impact
}

\author{
José Aderval Aragão, Francisco Prado Reis, \\ Felipe Matheus Sant'Anna Aragão, \\ lapunira Catarina Sant'Anna Aragão and \\ Sydney Correia Leão
}

Additional information is available at the end of the chapter

http://dx.doi.org/10.5772/intechopen.68824

\begin{abstract}
The venous system of the lower limbs has great structural and functional anatomical complexity which must be considered in different dysfunctions of this system. This complexity lies mainly in the venous return, which is changed from the upright position and ambulation and other factors such as level of physical activity, heart function, circulating blood volume, and ambient temperature. Anatomical description of soleus veins (SV) has received little attention from books' anatomy texts. These veins are intramuscular deep veins and known as the main chamber of the calf pump. Soleus veins have been implicated as the site for deep vein thrombosis (DVT). Detailed anatomical knowledge is required for early diagnosis using noninvasive ultrasound techniques. In the present work, we describe the anatomy of the veins that emerge from the ventral surface of the soleus muscle. Twenty-eight soleus muscles were dissected and 543 veins were found. The number of veins per leg ranged from 7 to 38 . The distribution of these veins per quadrant ranged from 0 to 12 . The greatest number of veins occurred in the upper lateral quadrant. Most of the soleus veins drained into the posterior tibial and fibular veins. The mean length of the soleus veins ranged from 0.907 to $2.804 \mathrm{~cm}$. We conclude that there is a wide variability in the distribution of soleus veins through the soleus muscle and its quadrants. The majority of the soleus veins drain into the tibial and fibular veins.
\end{abstract}

Keywords: anatomy, veins, soleus muscle

\section{Introduction}

The venous system of the lower limbs has biological characteristics and structural and functional complexity that can only be considered when addressing situations that lead to their 
dysfunction. The anatomy and physiology of the venous system of lower limbs are complex and its main characteristic is the fact that the venous return is influenced by change position, standing position, and ambulation. Venous return also depends on other factors, such as physical activity, cardiac function, circulating blood volume, and ambient temperature. These biological characteristics, belonging solely to human species, are important structural and functional complexity, since when man has adopted bipedal position as a preferred mode of locomotion, as does not possess a suitable elastic and fibrous tissue system in the lower limbs, adapted from efficient manner for the requirements of this position. The anatomical description of the soleus veins (SV) has received little attention from texts of anatomy books. Paturet [1] described the SV as satellites of the arteries. These veins, like the gastrocnemius veins, are studied by the anatomical and functional point of view as intramuscular deep vein, being known as the main chamber of the calf pump [2].

Kwakye [3] and Van Limborgh and Kwakye [4] divided the veins that receive drainage of the soleus muscle into two main groups: the posterior tibial and fibular. The fibular group receive two larger longitudinal veins, a lateral and another intermediate, that would have originated in the lower half of the soleus muscle across several small veins and end up in the posterior tibial veins.

For Kobak and Lev [5], the veins of the soleus muscle would drain mainly to the fibular veins as small soleus veins would end in the posterior tibial and fibular veins. Cocket [6] and Dodd and Cocket [7] described the venous sinuses formed inside the soleus muscle that would drain for short and loose veins that finally outfall in the tibial and fibular veins later.

According to Ukhov [8], intramuscular SV form three collector trunks: medial, intermediate, and lateral. In these collectors, the medial would be predominant, followed by intermediate and the lateral. At the height of the lower third of the soleus muscle, two to four veins that would pass by the posterior tibial veins emerge; rarely, it would happen with the presence of one venous trunk or four more veins.

The presence of venous sinuses inside the soleus muscle, ending up in venous collector trunks, was described by several authors [3, 4, 6-9]. Abramova and Chilaia [10] reported that more often there would be three venous sinuses in the soleus muscle: a lateral; midline, which would end the fibular vein; and medial, which would end in the posterior tibial veins.

Through a phlebographic study, Sequeira et al. [11] reported an average of $11.72 \mathrm{SV}$ on the right leg and 10.68 on the left leg. In dissecting bodies, Sequeira et al. [12] reported an average of 46.8 per leg. They studied the veins emerging from the anterior surface of the soleus muscle.

White et al. [13] reported that the calf muscle pump has been frequently discussed but incompletely defined. Functionally, it represents the mechanism by which blood in the deep calf veins is propelled cephalad. Physiologically, compartment pressures do not rise sufficiently during ambulation to adequately compress the deep calf veins and displace the blood they contain.

Black [14] reported that the deep veins of the calf include the tibial, peroneal, soleal, and gastrocnemius veins. The anterior tibial, posterior tibial, and peroneal veins are generally paired and are located on either side of a corresponding artery. Venous sinusoids within the deep calf musculature coalesce to form the soleal and gastrocnemius venous plexuses. These muscular venous sinuses are the primary collecting system of the calf muscle pump. Soleal sinuses 
typically communicate with the posterior tibial veins, whereas the gastrocnemius network coalesces into paired gastrocnemius veins that drain directly into the popliteal. The anterior and posterior tibial veins join with the peroneal veins to become the popliteal vein.

For Henry and Satiani [15], the calf muscle veins are deep veins in the distal lower extremity that are nonpaired and not associated with named tibial arteries. These veins make up a complex venous system of the musculature of the posterior leg and include the soleal and gastrocnemius veins that run as sinusoids within the muscles of the same name. The soleal sinusoids may drain into the mid peroneal or posterior tibial veins, whereas the gastrocnemius sinusoids may empty directly into the popliteal vein. In addition, these veins may communicate with the short saphenous veins through a series of perforators.

Calf muscle pump, according to Recek [16], is the motive force enhancing the return of the venous blood from the lower extremity to the heart. It causes displacement of the venous blood in both vertical and horizontal directions and generates ambulatory pressure gradient between thigh and lower leg veins and bidirectional streaming within calf perforators.

According to Uhl and Gillot [17], the muscular pumps are the true peripheral heart of the venous system of the lower limbs and play a crucial role in the venous return. The basic function of the venous system of the lower limbs is to ensure the return of the blood from the peripheral tissues to the heart and that in order to be efficient, the venous system is based on two mechanisms: the normal functioning of the venous valves (anti-reflux system against gravity) and a complex system of impulse-aspiration pumps, so-called venomuscular pumps.

Uhl and Gillot [17], highlighting the description 30 years ago by Gardner and Fox [18], reported that these pumps can be divided into four main parts, creating together a true chain of synchronized events: the foot pump, located in the lateral plantar veins; the leg pump, located in the soleus muscle; the gastrocnemial pump, acting at the popliteal level above the knee, these two latter pumps together are the calf pump, the most important pump of the limb; and finally, the thigh pumps: semimembranosus, biceps (posteriorly), and quadriceps muscle (anteriorly). The synchronization of the different venomuscular pumps during walk is crucial: the foot, then leg, popliteal, and finally thigh pumps.

Many authors have paid attention to the SV veins with respect to its role in the investigation of the location of deep vein thrombosis in the calf $[12,19-25]$. Thus, it has been a very usual anatomical study of the venous drainage of the soleus muscle from the knowledge of intramuscular veins.

\section{Material and methods}

Twenty-eight legs from 14 adult male human cadavers were used, which had been fixed and preserved in $10 \%$ formalin solution. The material was used in conformity with Law 8501 of November 30, 1992, which provides for the utilization of unclaimed cadavers for scientific research or study purposes. The present study was approved by the Research Ethics Committee of the Health Sciences University of Alagoas, Brazil, under protocol no. 038/02. Cadavers that presented macroscopically detectable pathological alterations on the lower limbs were excluded from the study. 
The anatomical layers of the posterior region of the leg were dissected until the gastrocnemius muscle and the posterior surface of the soleus muscle had been exposed. On this posterior face, two transversal lines were traced out to divide the muscle into three levels: upper, middle, and lower. A median longitudinal line was traced out to intersect with the transversal lines, thereby resulting in the division of the surface of the soleus muscle into six quadrants: superior medial (QSM) and superior lateral (QSL); middle medial (QMM) and middle lateral (QML); and inferior medial (QIM) and inferior lateral (QIL), as shown in Figure 1. The muscle was taken out distally, and the veins without the aid of optical instruments were dissected on their ventral surface in the distal-to-proximal direction. A digital pachymeter was utilized to measure the length of all the dissected veins. The anatomical findings were recorded in tables and by means of digital photographs.

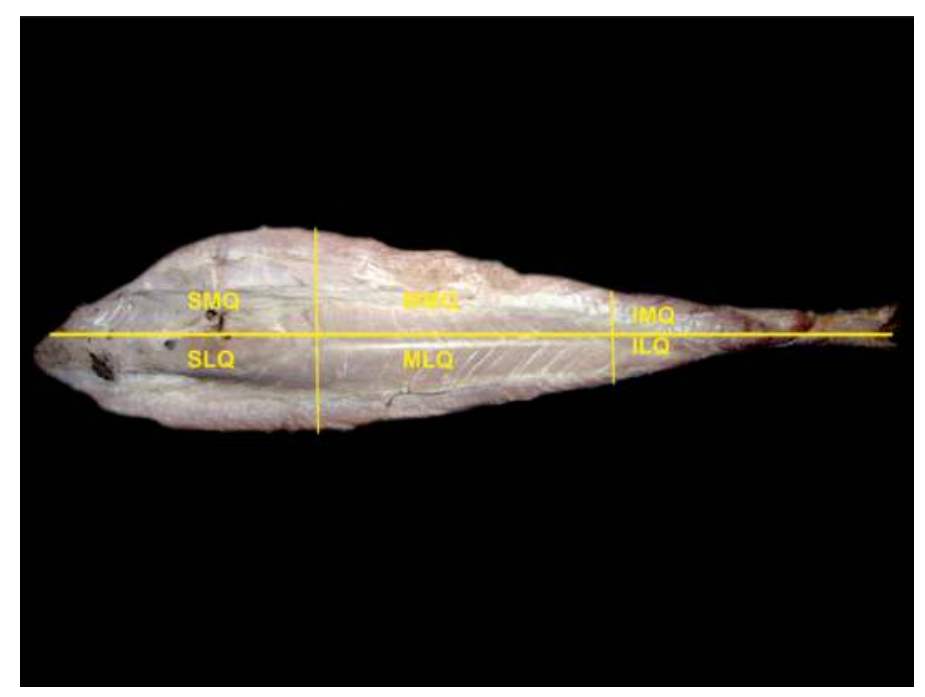

Figure 1. The soleus muscle divided into six quadrants. SMQ, superior medial quadrant; SLQ, superior lateral quadrant; $M M Q$, middle medial quadrant; MLQ, middle lateral quadrant; IMQ, inferior medial quadrant; and ILQ, inferior lateral quadrant.

\section{Results}

These results corresponded to the dissection of 28 legs. We found a total of $543 \mathrm{SV}$ that emerged from the anterior face of the soleus muscle: 268 in the right legs and 275 in the left legs. The mean numbers of veins in the right and left legs were similar. In the right leg, the numbers ranged from 8 to 38 , with a mean of 19.1. In the left leg, the numbers ranged from 7 to 36 , with a mean of 19.6 (Table 1 ).

The distribution of SV by level and quadrant presented variations, with a maximum range of 12. The variations were less accentuated between the quadrants of the lower level of the muscle and greater between the middle quadrants and superior quadrants. The smallest number 


\begin{tabular}{llll}
\hline Leg & Number of veins & Range & Mean \\
\hline Left & 268 & $8-38$ & 19.142 \\
Right & 275 & $7-36$ & 19.642 \\
Total & 543 & & \\
\hline
\end{tabular}

Table 1. Veins that emerge from the ventral face of the soleus muscle.

of SV per leg and quadrant (16) was found in the QIL of the right leg and the larger (77) in the QMM of the right leg. In these same quadrants, the lowest (1.1) and highest (5.5) means (Table 2) were found.

The SV most frequently drained into the medial posterior tibial vein (VTPM, Figure 2), lateral posterior tibial vein (VTPL, Figure 3), lateral fibular vein (VFL, Figure 4), and medial fibular vein (VFM, Figure 5). On the other hand, the short saphenous vein (VSP) and the tibiofibular trunk (TTF) received the smallest numbers of SV. Some SV also terminated simultaneously in more than one vein (Figure 6). This finding was most frequent in relation to the VTPM and VTPL (Table 3). Varying numbers of SV also terminated in the medial and lateral anterior tibial veins (VTAM, VTAL), SV, gastrocnemius vein (VG Figure 7), and popliteal vein (VP Figure 8). In 43 soleus veins, it was not possible to recognize their termination.

\begin{tabular}{|c|c|c|c|c|}
\hline Quadrant & Leg & Number of veins & Variation & Mean \\
\hline \multirow[t]{2}{*}{ IMQ } & Right & 18 & $0-4$ & 1.285 \\
\hline & Left & 28 & $0-4$ & 2.000 \\
\hline Total & & 46 & & \\
\hline \multirow[t]{2}{*}{ ILQ } & Right & 16 & $0-4$ & 1.142 \\
\hline & Left & 23 & $0-4$ & 1.642 \\
\hline Total & & 39 & & \\
\hline \multirow[t]{2}{*}{ MMQ } & Right & 77 & $2-12$ & 5.500 \\
\hline & Left & 57 & $0-8$ & 4.071 \\
\hline Total & & 134 & & \\
\hline \multirow[t]{2}{*}{ MLQ } & Right & 31 & $0-6$ & 2.214 \\
\hline & Left & 37 & $0-8$ & 2.642 \\
\hline Total & & 68 & & \\
\hline \multirow[t]{2}{*}{ SMQ } & Right & 56 & $1-12$ & 4.000 \\
\hline & Left & 54 & $0-8$ & 3.857 \\
\hline Total & & 110 & & \\
\hline \multirow[t]{2}{*}{ SLQ } & Right & 70 & $0-8$ & 5.000 \\
\hline & Left & 76 & $0-11$ & 5.428 \\
\hline Total & & 146 & & \\
\hline
\end{tabular}

Table 2. Number, variation, and mean number of soleus veins per quadrant and legs. 


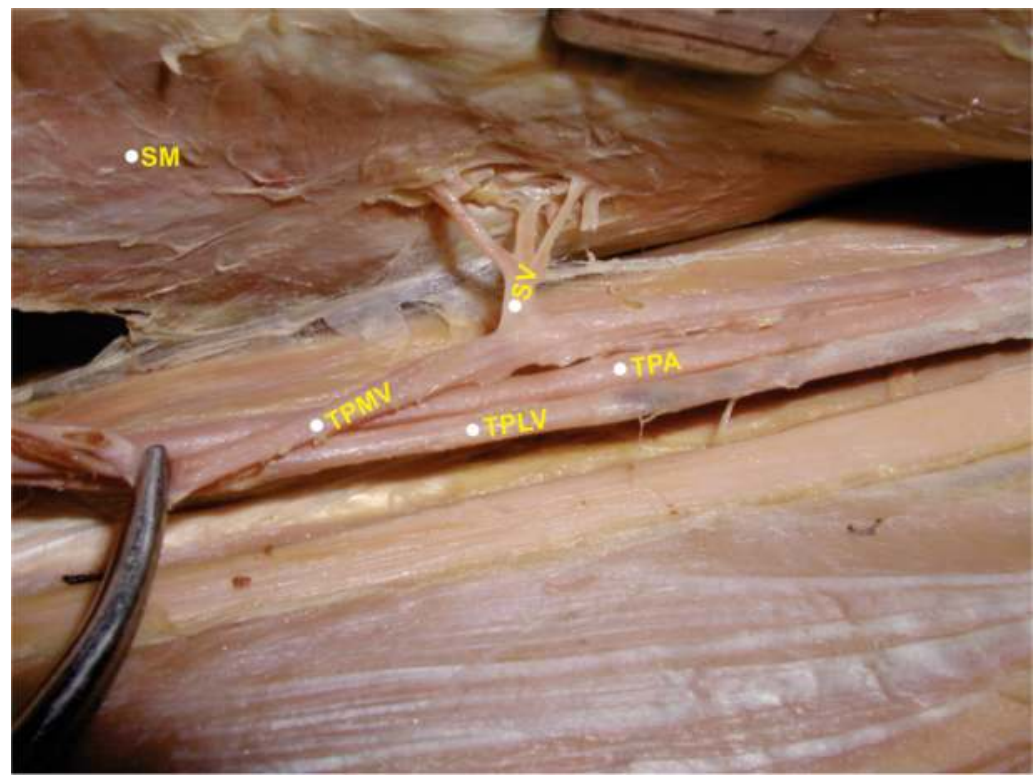

Figure 2. Soleus vein termination into the medial posterior tibial vein. SM, soleus muscle; SV, soleus vein; TPMV, tibial posterior medial vein; TPLV, tibial posterior lateral vein; and TPA, tibial posterior artery.

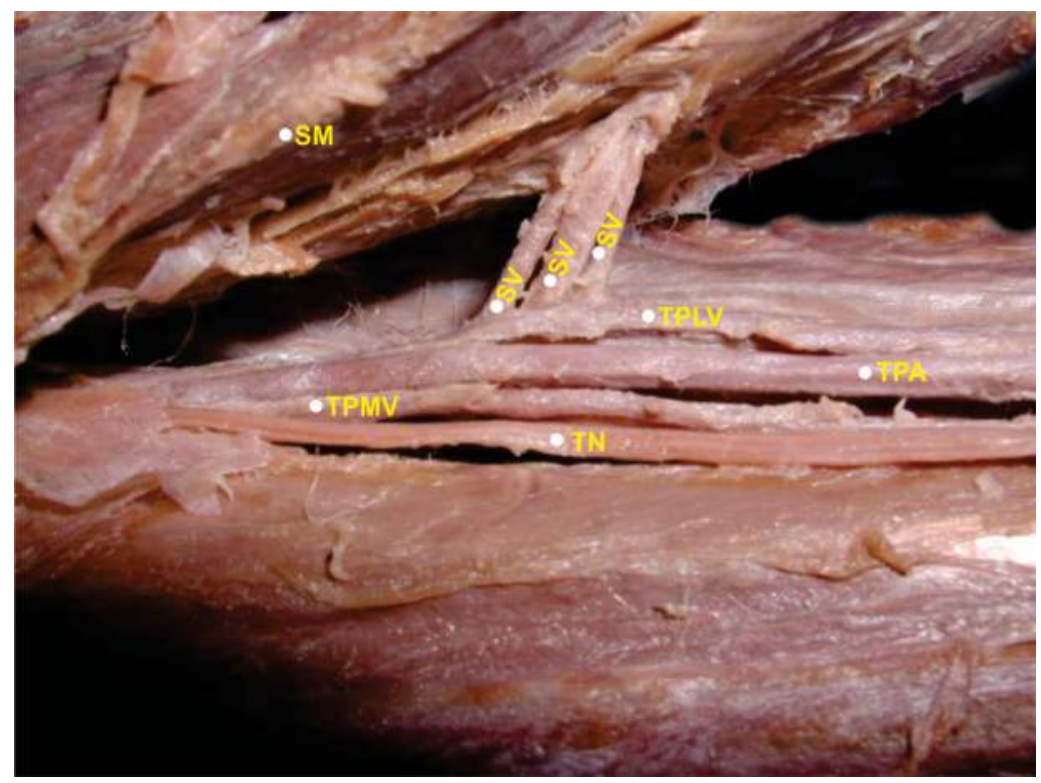

Figure 3. Soleus vein termination into the lateral posterior tibial vein. SM, soleus muscle; SV, soleus vein; TPMV, tibial posterior medial vein; TPLV, tibial posterior lateral vein; TPA, tibial posterior artery; and TN, tibial nerve. 


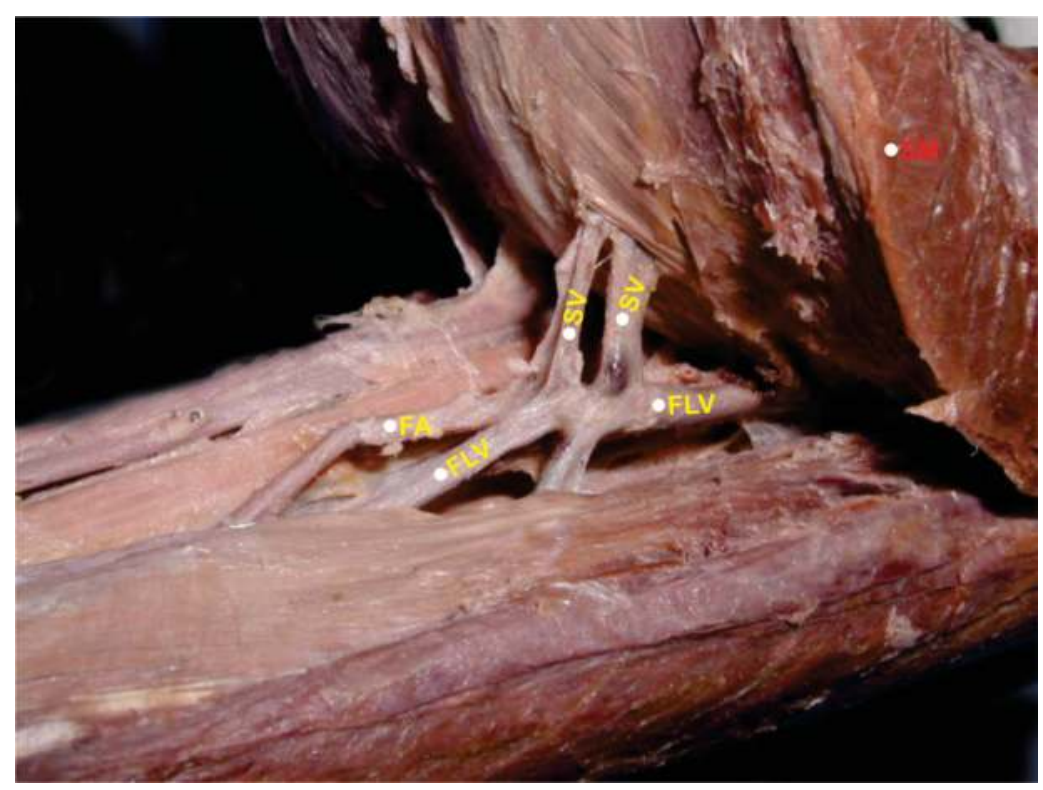

Figure 4. Soleus vein termination into the lateral fibular vein. SM, soleus muscle; SV, soleus vein; FLV, fibular lateral vein; and FA, fibular artery.

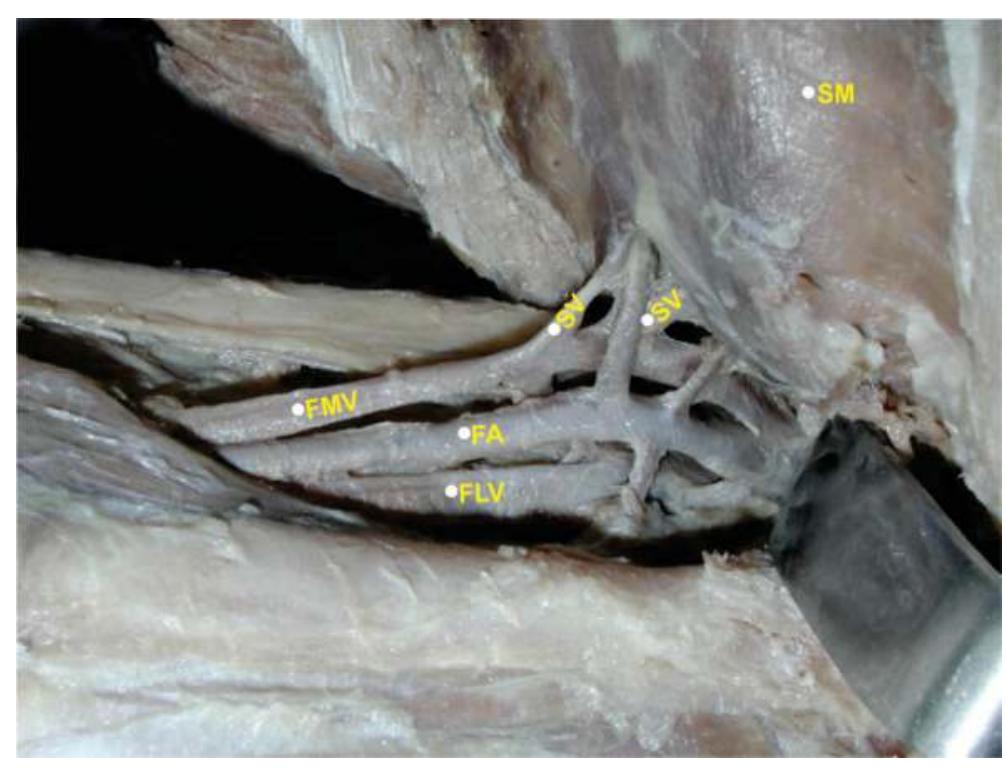

Figure 5. Soleus vein termination into the medial fibular vein. SM, soleus muscle; SV, soleus vein; FMV, fibular medial vein; FLV, fibular lateral vein; and FA, fibular artery. 


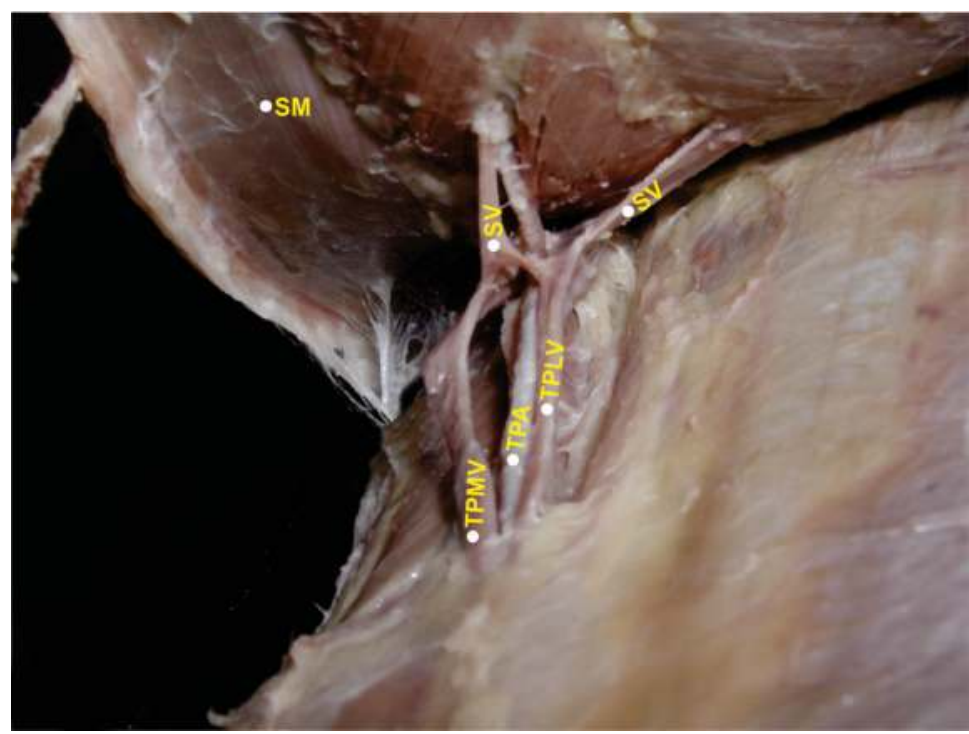

Figure 6. Simultaneous termination of the soleus vein into the medial and lateral posterior tibial veins. SM, soleus muscle; SV, soleus vein; TPMV, tibial posterior medial vein; TPLV, tibial posterior lateral vein; and TPA, tibial posterior artery.

\begin{tabular}{llll}
\hline Veins & Right leg $(\mathbf{n}=\mathbf{1 4})$ & Left leg $(\mathbf{n}=\mathbf{1 4})$ & Total \\
\hline TPMV & 75 & 66 & $\mathbf{1 4 1}$ \\
TPLV & 55 & 51 & $\mathbf{1 0 6}$ \\
FMV & 20 & 24 & $\mathbf{4 4}$ \\
FLV & 58 & 45 & $\mathbf{1 0 3}$ \\
TAMV & 09 & 02 & $\mathbf{1 1}$ \\
TALV & 02 & 03 & $\mathbf{0 5}$ \\
PV & 01 & 04 & $\mathbf{0 5}$ \\
SPV & 01 & 01 & $\mathbf{0 2}$ \\
TPMV + TPLV & 06 & 10 & $\mathbf{1 6}$ \\
TPLV + FMV & 01 & 02 & $\mathbf{0 3}$ \\
FMV + FLV & 04 & 03 & $\mathbf{0 7}$ \\
TFT & 00 & 02 & $\mathbf{0 2}$ \\
SV & 06 & 07 & $\mathbf{1 3}$ \\
GV & 14 & 05 & $\mathbf{1 9}$ \\
Others & 13 & 30 & $\mathbf{4 3}$ \\
\hline
\end{tabular}

TPMV, tibial posterior medial vein; TPLV, tibial posterior lateral vein; FMV, fibular medial vein; FLV, fibular lateral vein; TAMV, tibial anterior medial vein; TALV, tibial anterior lateral vein; PV, popliteal vein; SPV, small saphenous vein; TFT, tibiofibular trunk; SV, soleus vein; GV, gastrocnemius vein

Table 3. Drainage of soleus muscle. 


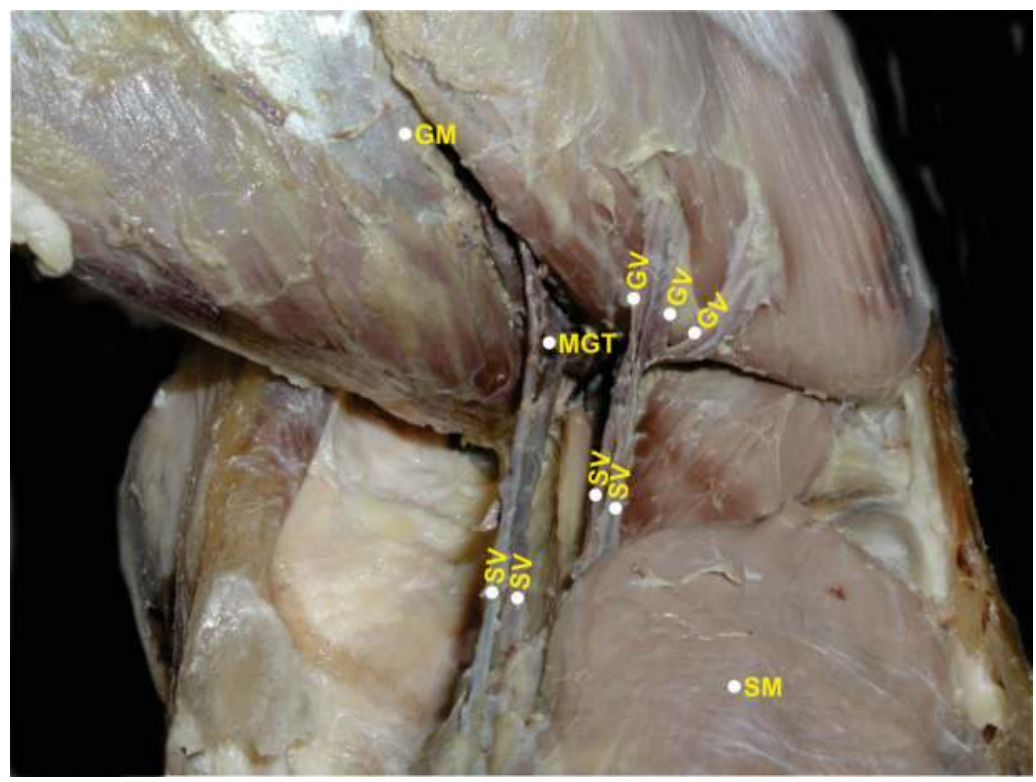

Figure 7. Soleus vein termination into the main gastrocnemius vein and trunk. SM, soleus muscle; SV, soleus vein; GM, gastrocnemius muscle; GV, gastrocnemius vein; and MGT, main gastrocnemius trunk.

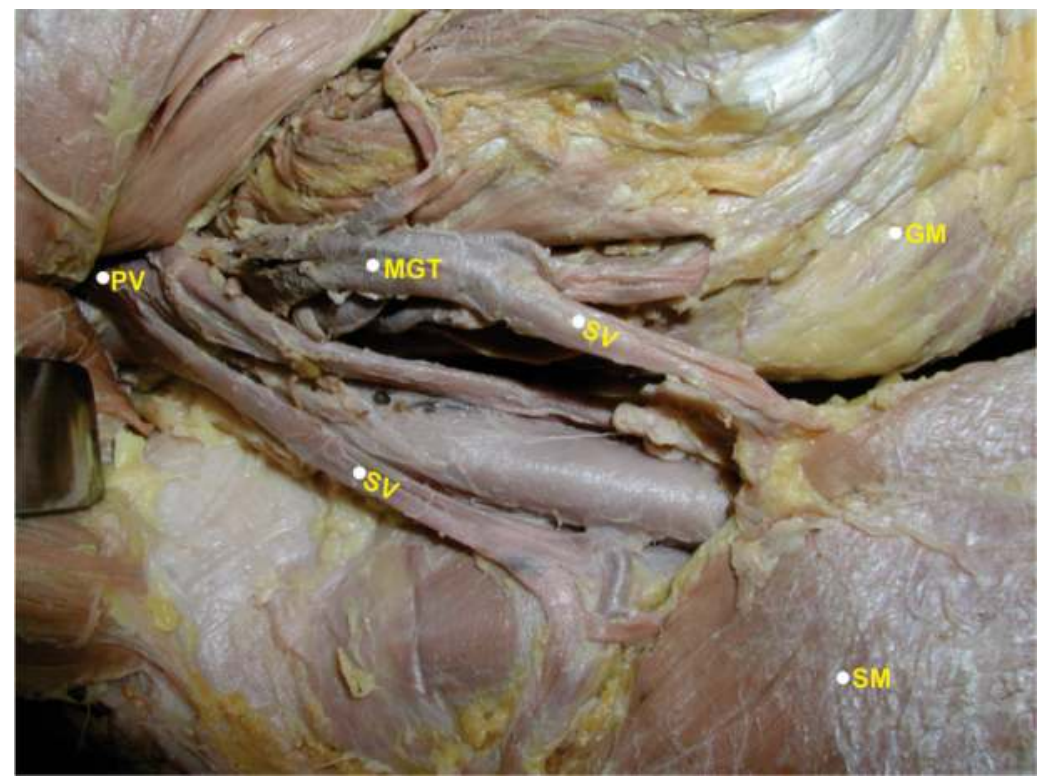

Figure 8. Soleus vein termination into the popliteal vein and main gastrocnemius trunk. SM, soleus muscle; SV, soleus vein; GM, gastrocnemius muscle; PV, popliteal vein; and MGT, main gastrocnemius trunk. 
The mean lengths of the SV ranged from 0.907 to $2.804 \mathrm{~cm}$. The smallest length was found in the QMM of the right leg and the greatest length in the QIL of the left leg (Table 4). The mean length of the SV was least $(1.139 \mathrm{~cm})$ in the middle level of the soleus muscle of the right leg and greatest $(2.172 \mathrm{~cm})$ in the lower level of the soleus muscle of the left leg (Table 5). This greatest mean length was also similar to what was found at the lower level of the right leg muscle.

\begin{tabular}{llllllll}
\hline Leg & $\mathrm{n}$ & QIM & QIL & QMM & QML & QSM & QSL \\
\hline Right & 14 & 1.627 & 2.550 & 0.907 & 1.716 & 1.228 & 1.328 \\
Left & 14 & 1.653 & 2.804 & 1.062 & 1.662 & 1.475 & 1.436 \\
Total & 28 & & & & & & \\
\hline
\end{tabular}

Table 4. Mean length $(\mathrm{cm})$ of the extramuscular veins of the soleus muscle per quadrant.

\begin{tabular}{lllll}
\hline Leg & $\mathbf{n}$ & Third & & \\
\hline & & Inferior & Medium & Superior \\
\hline Right & 14 & 2.061 & 1.139 & 1.284 \\
Left & 14 & 2.172 & 1.339 & 1.454 \\
Total & 28 & & & \\
\hline
\end{tabular}

Table 5. Mean length $(\mathrm{cm})$ of the extramuscular veins of the soleus muscle per third of the height of the muscle.

\section{Discussion}

A general systematization of the SV anatomy described by (White et al. [13]), was reported by Kwakye [3]. More recently, among other authors, Uhl and Gillot [17] described an overall systematization of the anatomy of the SV. For those authors, these veins, the SV, are clearly visible inside the muscle, each part being divided into central, close to the septum and peripheral, located laterally. The medial veins of the soleus are smaller than the lateral veins of the soleus and are oriented horizontally in the peripheral part of the muscle and vertically in the central part. These vertical and central veins join the midline at the proximal part of the muscle to connect the fibular veins more laterally. The lateral view shows the large volume of the lateral veins of the soleus, directed vertically. They join in several trunks ending in the fibular veins, above the arcade of the long flexor of the hallux muscle. This explains why the fibular veins are much larger above this arcade. Below, they are contained into the fibrous, inextensible fibular canal. Above, they are dilated due to the arrival of those large lateral veins of the soleus.

Uhl and Gillot [17] concluded, in summary, that the drainage of the veins of the soleus muscle is divided into two parts: the medial veins horizontally into the posterior tibial veins and the lateral veins vertically into the fibular veins. 
Uhl and Gillot [17] also reported on the finding of a, not described previously, superior vein or dorsal vein of the soleus (DVS). The specific landmark of this vein is the belly of the plantaris muscle, located between the gastrocnemius and soleus muscles. It arises from the lower part of the lateral prolongation of the linea aspera and from the oblique popliteal ligament of the knee joint. It forms a small fusiform belly, from 7 to $10 \mathrm{~cm}$ long, ending in a long slender tendon that crosses obliquely between the two muscles of the calf. It runs along the medial border of the calcaneus tendon to be inserted with it into the posterior part of the calcaneus.

In the present study, the anatomy of the SV was described in relation to their emergence on the anterior surface of the soleus muscle. This approach has also been performed by Sequeira et al. [11, 12, 26] and Reis et al. [27]. So in that way, most of our discussion was held at the work of these single authors, in Brazil, to carry out this type of study for soleus veins.

Kageyama et al. [28] and Ro and Kageyama [29] reported that the soleal vein contains over 10 multibranched veins in each leg and they are roughly subclassified into three groups: (1) centralis, (2) medialis, and (3) lateralis.

Ohgi and Ohgi [30] investigated the relationships between specific distributions of isolated thrombosis of the soleus vein sole thrombosis (SVT) and risk factors; in the vein classification, the soleus muscle was divided into six circulatory regions and intramuscular veins were divided into six groups - proximal, lateral, central, medial, distal medial, and distal lateral veins-based on the circulatory regions and deep veins communicated with intramuscular veins in these regions. Despite the similar approach, these authors did not, however, describe any morphometric data or the topography and distribution of the extramuscular soleus veins.

The mean numbers of SV per leg and per individual were quite different. We found a mean of 19.34 SV per leg and 38.68 per individual, while the means cited by those authors were 46.76 and 93.52, respectively.

We emphasize that the authors did not make any reference to variations in the numbers of veins of each of the legs. In relative terms, we found that the percentages of SV per leg were similar to those of Sequeira et al. [11, 12]. The number of SV increased from the lower level to the upper level. Together, the middle and upper levels presented a concentration of $84.34 \%$ of all of the SV, with $47.14 \%$ in the upper level. This may be related with the anatomy of the soleus muscle.

With regard to the distribution of SV per quadrant, our findings differ from those of Sequeira et al. [11, 12]. These authors found that $7.39 \%$ of them were located in the QMM and 6.65\% in the QSL. These data are different from the phlebographic findings of Sequeira et al. [11], in which the SV locations were 29.1\% in the QML and 27.4\% in the QMM. Our findings were that $26.8 \%$ these veins were located in the QSL and 24.6\% in the QMM. Among the quadrants, $53.4 \%$ of the veins were located medially and $46.59 \%$ laterally.

Around $75.7 \%$ of the SV drained into the tibial and fibular veins. This pattern appears to be in agreement with that described by authors as Van Limborgh and Kwakye [4], Kobak and Lev [5], Henry and Satiani [15], Black [14], and Uhl and Gillot [17]. Out of the $47.5 \%$ of the 
SV that terminated in the tibial veins, $27.1 \%$ terminated in the VTPM and $20.3 \%$ in the VTPL. With regard to the fibular veins, $19.8 \%$ of the SV terminated in the VFL and $8.4 \%$ in the VFM. Using phlebography, Sequeira et al. [11] described a pattern of predominant termination of SV in the fibular vein. The mean length of the SV according to the level of the soleus muscle was greatest at the lower level of the left leg muscle. The smallest mean length was found at the middle level of the right leg muscle.

We present here a static anatomical aspect of the SV. The authors have used the anatomical aspect of soleal and gastrocnemius vein to explain clinically and physiopathologically the involvement of these vessels in the deep vein thrombosis (DVT) and other disorders that occur in the calf muscle pump.

Henry and Satiani [15] highlighted the significant impact of DVT on the worldwide population health. They divided deep thrombosis of the veins of the lower limbs into proximal or axial DVT and calf DVT. This discussion was related to calf muscle venous thrombosis (CMVT) or DVT involving isolated gastrocnemius and soleal vein thrombosis as well as in combination with proximal or axial DVT.

Keijsers et al. [31] admitted that the collapsibility of the veins and the dynamics of the venous valves that direct the blood toward the heart and shield hydrostatic pressure are believed to be the main physiological factors in the muscle pump effect. Thus they studied the dynamics of calf muscle pump function during a muscle contraction using the different model configurations that were reported in four sections which examine the course of the deep venous collapse, the effect of venous valves, the effect of hydrostatic pressure, and the importance of the superficial system, respectively. They concluded that the model developed was able to predict the increase in venous return during muscle contraction. As the proximal valves close during the relaxation phase, reflux is prevented, which without valves resulted in a loss of $53 \%$ of effective venous return. Furthermore the closing of the valves increases the perfusion in the relaxation phase. Finally, the inclusion of the superficial venous system demonstrates the role of the superficial veins in maintaining arterial inflow during muscle contraction and decreasing refilling time by $37 \%$ during relaxation.

Williams et al. [32], conducted a review whose primary objective was the evaluate the relationship between calf muscle pump function and the onset and progression of chronic vascular disease (CVD), using the available literature. The authors identified a correlation between calf muscle pump dysfunction and CVD, whose data implied calf muscle pump impairment as a clinical manifestation associated with symptomatic disease. According to available literature, they concluded that the linear relationship between the clinical manifestation of CVD with the ejection fraction (EF) is consistent, but it is not conclusive; it supports the association between calf muscle pump dysfunction and objective measures of CVD severity.

We believe that our main contribution was the description of the emerging veins of the anterior surface of the soleus muscle. Thus our focus was to identify the large number of veins, some of which next to arteries form vascular pedicle and were draining. These veins are likely to be more accessible to the image and surgical dissections. This can be a contribution to assist vascular and plastic surgeons as well as those radiologists and for future hemodynamic studies. 


\section{Final considerations}

The present anatomical findings as the veins of the soleus muscle exemplify the complexity of the human venous system, particularly of the lower limbs, whose veins have significant role in physiology in the venous return as well as of its involvement in the origin and development of physiopathology of deep vein thrombosis and chronic vascular disease.

\section{Acknowledgements}

This chapter features content reproduced from authors' earlier publication on this topic [27].

\section{Author details}

José Aderval Aragão ${ }^{1,2 *}$, Francisco Prado Reis², Felipe Matheus Sant'Anna Aragão ${ }^{3}$, Iapunira Catarina Sant'Anna Aragão ${ }^{3}$ and Sydney Correia Leão ${ }^{4}$

*Address all correspondence to: jaafelipe@infonet.com.br

1 Federal University of Sergipe (UFS), Aracaju, Brazil

2 Tiradentes University (UNIT), Aracaju, Brazil

3 University Center of Volta Redonda(UNIFOA), Brazil

4 Federal University of São Paulo (UNIFESP), Brazil

\section{References}

[1] Paturet G. Traité d'anatomie humaine. Paris: Masson; 1951. 859 p

[2] Browse NL, Burnand KG, Irvine AT, Wilson NM. Fisiologia e anatomia funcional. In: Browse NL, Burnand KG, Irvine AT, Wilson NM, editors. Doenças venosas. 2nd ed. Rio de Janeiro: Di-Livros; 2001. p. 47-59

[3] Kwakye LB. Gross anatomy of the soleus veins. Acta Morphologica NeerlandoScandinavica. 1972;9(4):281-294. PMID: 5055989

[4] Van Limborgh J, Kwakye LB. Anatomie normale des veines soleaires chez lês personnes agées. Phlébologie. 1975;28(2):273-9

[5] Kobak M, Lev M. Anatomy of the deep venous system of the popliteal fossa and lower leg. AMA Archives of Surgery. 1954;68(3):350-354. PMID: 13137693

[6] Cockett FB. The pathology and treatment of venous ulcers of the leg. British Journal of Surgery. 1955;43(179):260-78. PMID: 13284261 
[7] Dodd H, Cockett FB. Anatomy of the veins of the lower limb. In: Dodd H, Cockett FB, editors. The Pathology and Surgery of the Veins of the Lower Limb. 2nd ed. Edinburgh: Churchill Livingstone; 1976. pp. 18-24

[8] Ukhov II. Veins of the soleus and their relationship with the organ structure. Arkhiv Anatomii, Gistologii I Embriologii. 1974;67(7):104-110. PMID: 4455143

[9] Coito AMF. Particularidades anatômicas do sistema venoso dos membros inferiores. Gazeta Médica Portuguesa.1959;12(2):141-194

[10] Abramova AA, Chilaia SM. Structure of the venous sinuses of M. soleus and their role in the origin of thrombosis of the deep veins in the lower limbs. Arkhiv Anatomii, Gistologii I Embriologii. 1967;53(9):63-67. PMID: 5614568

[11] Sequeira CMG, Martins FG, Andrade JA, Mayall ACDG, Mayall RC. Estudo flebográfico das veias soleares. Revista de angiologia e cirurgia vascular 2005;1(1):15-23

[12] Sequeira CMG, Juliano Y, Novo NF, Mayall RC, Júnior FM. Veias soleares: bases anatômicas e seu papel na origem da trombose venosa profunda em membro inferior. Revista da Associação Médica Brasileira. 2007;53(4):305-310. DOI: 10.1590/S0104-42302007000400014

[13] White JV, Katz ML, Cisek P, Kreithen J. Venous outflow of the leg: Anatomy and physiologic mechanism of the plantar venous plexus. Journal of Vascular Surgery. 1996 Nov;24(5):819-24. PMID: 8918329

[14] Black CM. Anatomy and physiology of the lower-extremity deep and superficial veins. Techniques in Vascular and Interventional Radiology. 2014 Jun;17(2):68-73. PMID: 24840960. DOI: 10.1053/j.tvir.2014.02.002

[15] Henry JC, Satiani B. Calf muscle venous thrombosis: A review of the clinical implications and therapy. Vascular and Endovascular Surgery. 2014 Jul-Aug;48(5-6):396-401. PMID: 25027613. DOI: 10.1177/1538574414541704

[16] Recek C. Conception of the venous hemodynamics in the lower extremity. Angiology. 2006 Oct-Nov;57(5):556-563. PMID: 17067977. DOI: 10.1177/0003319706293117

[17] Uhl JF, Gillot C. Anatomy of the veno-muscular pumps of the lower limb. Phlebology. 2015 Apr;30(3):180-93. PMID: 24415543. DOI: 10.1177/0268355513517686

[18] Gardner AM, Fox RH. The venous pump of the human foot: preliminary report. Bristol Medico-Chirurgical Journal or Bristol Med Chir J 1983;98:109-112. PMID: 6616290

[19] Ohgi S, Tachibana M, Ikebuchi M, Kanaoka Y, Maeda T, Mori T. Pulmonary embolism in patients with isolated soleal vein thrombosis. Angiology. 1988;49(9):759-764. PMID: 9756428

[20] Krünes U, Teubner K, Knipp H, Holzapfel R. Thrombosis of the muscular calf veinsReference to a syndrome which receives little attention. Vasa. 1988;27(3):172-175. PMID: 9747154

[21] Labropoulos N, Webb KM, Kang SS, Mansour MA, Filliung DR, Size GP, Buckman J, Baker WH. Patterns and distribution of isolated calf deep vein thrombosis. Journal of Vascular Surgery. 1999;30(5):787-791. PMID: 10550175 
[22] Sprayegen S, Koenigsberg K, Haimovici H. Flebografia contrastada e imagens ultrasônicas venosas. In: Haimovici H, editor. Cirurgia vascular: princípios e técnicas. 4th ed. Rio de Janeiro: Di-Livros; 1999. pp. 1172-1190

[23] Hollerweger A, Macheiner P, Rettenbacher T, Gritzmann N. Sonographic diagnosis of thrombosis of the calf muscle veins and the risk of pulmonary embolism. Ultraschall in der Medizin. 2000;21(2):66-72. PMID: 10838706. DOI: 10.1055/s-2000-8929

[24] Garrido MBM. Anatomia médico-cirúrgica do sistema venoso dos membros inferiores. In: Maffei FHA, editor. Doenças vasculares periféricas. 3rd ed. São Paulo: Medisi; 2002. pp. 133-167

[25] Cohen BJ, Wood DL. Vasos sanguíneos e circulação do sangue. In: Cohen BJ, Wood DL, editors. O corpo humano na saúde e na doença. 1st ed. São Paulo: Manole; 2002. pp. 267-290

[26] Sequeira CMG, Miranda Jr F, Mayall RC. Estudo da terminação das veias soleas no homem. Jornal Vascular Brasileiro. 2003;2(S1):39

[27] Reis FP, Aragão JA, de Figueiredo LF, Miranda F Jr, Nunes MA, Feitosa VL. Venous drainage of the soleus muscle. Surgical and Radiologic Anatomy. 2008 Jun;30(4):341-345. PMID: 18330491. DOI: 10.1007/s00276-008-0333-6

[28] Kageyama N, Ro A, Tanifuji T, Fukunaga T. Significance of the soleal vein and its drainage veins in cases of massive pulmonary thromboembolism. Annals of Vascular Diseases. 2008;1(1):35-39. PMID: 23555336. DOI: 10.3400/avd.AVDoa07004. Erratum in: Ann Vasc Dis. 2008;1(2):122

[29] Ro A, Kageyama N. Clinical significance of the soleal vein and related drainage veins, in calf vein thrombosis in autopsy cases with massive pulmonary thromboembolism. Annals of Vascular Diseases. 2016;9(1):15-21. PMID: 27087868. DOI: 10.3400/avd. oa.15-00088

[30] Ohgi S, Ohgi N. Relationship between specific distributions of isolated soleal vein thrombosis and risk factors. Annals of Vascular Diseases. 2014;7(3):246-255. PMID: 25298825. DOI: 10.3400/avd.oa.14-00077

[31] Keijsers JM, Leguy CA, Huberts W, Narracott AJ, Rittweger J, van de Vosse FN. A 1D pulse wave propagation model of the hemodynamics of calf muscle pump function. International Journal for Numerical Methods in Biomedical Engineering. 2015 Jul;31(7):e02716. PMID: 25766693. DOI: 10.1002/cnm.2714

[32] Williams KJ, Ayekoloye O, Moore HM, Davies AH. The calf muscle pump revisited. Journal of Vascular Surgery: Venous and Lymphatic Disorders. 2014 Jul;2(3):329-34. DOI: 10.1016/j.jvsv.2013.10.053 
